\title{
The Pricing of IPO by Investment Banks and Venture Capital: A Theoretical Model
}

\author{
Huanran Kong \\ Mechanical Engineering School of Mechanical Engineering, China University of Mining and Technology, Xuzhou, China \\ Email: zhujunmin.2008@163.com
}

How to cite this paper: Kong, H.R. (2018) The Pricing of IPO by Investment Banks and Venture Capital: A Theoretical Model. Open Journal of Social Sciences, 6, 209-221. https://doi.org/10.4236/jss.2018.610017

Received: September 13, 2018

Accepted: October 28, 2018

Published: October 31, 2018

Copyright $\odot 2018$ by author and Scientific Research Publishing Inc. This work is licensed under the Creative Commons Attribution International License (CC BY 4.0).

http://creativecommons.org/licenses/by/4.0/

\begin{abstract}
The venture capitalists provide supervision and certification service for shareholding enterprises, which reduce the information asymmetry and attract more high quality investment banks. Thus, the price is close to the market price when the enterprise enters the market and under-pricing is avoided thereby. Based on the supervision and certification hypothesis, this paper builds a pricing model of investment banks and venture capital to explain the pricing mechanism of investment bank, investment risk pricing mechanism and the causes of underpricing.
\end{abstract}

\section{Keywords}

Investment Banks, Venture Capital, Pricing, Underpricing

\section{Introduction}

The venture capital market is a highly competitive market. There are differences in the links and networks formed between venture capital and other institutions in the capital market. This difference makes the difference between "products and services" provided by venture capital for venture companies [1]. The benefits brought by venture companies are also different, which are called the market power of venture capital. Venture capital is a special investment institution that not only provides equity financing for financing companies, but also provides management and consulting services for financing enterprises, and plays an important role in the management and decision-making process of venture enterprises. Because venture capital often participates in the IPO market, it may have long-term relationships with other players in the IPO market, such as underwriters, institutional investments, and securities analysts. As a regular participant in the IPO market, venture capital has the potential to attract other participants, such as attracting high-quality investment banks and institutional investors to 
participate in the IPOs of the venture companies they invest in, and attract more analyst attention [2]. This kind of solid relationship helps the venture companies to successfully carry out IPOs and obtain higher stock prices in the secondary market, which is conducive to the exit of venture capital and enhances its reputation [3]. Their reputation is critical to the success of raising the next venture capital fund.

As a new type of professional financial intermediation, venture capital is different from traditional financing channels, which is not only for mature enterprises with strong stability, but invests in innovative enterprises with high growth and high risks to solve the financing of innovative SMEs problem [4].

\section{Literature Review}

Dennis (1973) found an appearance that 250 IPOS' first day rate of return was too high in America from 1965 to 1969. Researchers explained that IPO underpricing theory mainly included the view of primary and secondary market: the primary market theory hypothesis including that Winner's Curse, Signal Transmission, Entrusted Agency, Investment Banks Reputation, etc. And secondary market hypothesis including that Speculative Bubble, Investment Banks To Support Hypothesis, etc. Rock $(1982,1986)$ proposed the hypothesis of Winner's Curse and thought that IPO underpricing issues for compensating the inventors who are at an information disadvantage. The investors divided into informed ones who fully grasp stock-related information and uninformed ones who do not familiar with the relevant information at all in his views. There may be a discrepancy when the uninformed investors in judging the value of new shares, and tend to apply for overvalued stocks, which resulting in a mismatch between the risks assumed and the profits obtained, and cracking down on the enthusiasm of uninformed investors to form a "winner curse", that is who informed investors only purchase a few number of undervalued new shares which are sought after by investors, and most of them which that shows overvalued and unexpected, resulting in low the average yield of non-informed investors in new share subscriptions, so uninformed investors would participate in new share subscriptions unless the underpricing of new shares compensates for the losses caused by information asymmetry [5]. That is why that the enterprise attracts uninformed investors to participate in the subscription in the form of underpricing. The impact of venture capital on the IP0 pricing and underpricing rate of the invested companies mainly includes the "supervision hypothesis" proposed by Barry et al. and the "certification hypothesis" proposed by Megginson et al. Barry et al. (1990) argue that venture capitalists provide intensive supervision services for companies, and venture capital-backed corporate IPOs can attract higher quality investment banks, that lead to lower IPO underpricing rates. Megginson and Weiss (1991) argue that venture capital is a third-party information verification agency between the issuing company and the investor. By reducing information asymmetry, venture capitalists can reduce the listing cost of the issuing company, resulting in lower underpricing of the issuing enterprise 
IPO and underwriting rate.

The existing research has not explored the mechanism of interest between listed companies, investment risk, investment banks and investors, nor explained the mechanism of the impact of investment risk about underpricing. This paper builds a gaming model of venture capital and investment bank primary market pricing by referring to Rock's basic hypothesis about informed investors and uninformed investors, to explain the pricing and underpricing of investment banks and venture capital in the process of enterprise IPO.

\section{Model Hypothesis}

Suppose a pre-development of a startup is funded by a venture capital institution. It faces new investment opportunities in development, but neither itself nor the venture capital institution has the ability to reinvest the enterprise. So the enterprise needs finance through IPO.

Enterprises have strong information asymmetry in the IPO process. As an intermediary between listed companies and external investors, underwriters play an important role in reducing information asymmetry. The supervision of the underwriters may reduce agency costs and improve the company's operating performance, thereby increasing the company's value. However, the underwriters and IPO companies are a repetitive game under the limited competition conditions in the listing process. The underwriters' future survival status and income are directly related to the quality of the underwriters. Therefore, from the perspective of their own reputation, the underwriters are When IPO companies provide services, they will pay special attention to the true quality of these companies. Thus, a good reputation underwriter can help to increase investor confidence in IPO companies.

The long-term cooperation between venture capital and securities underwriters is not only conducive to obtaining more IPOs in the future, but also helps enterprises to better complete the preparatory work for listing. Near the end of the venture capital lock-up period, the underwriters will provide some services for their smooth exit. Based on the above analysis, this paper proposes the hypothesis:

A1: According to whether the venture capital has purchased the equity of the enterprise before the company publicly issues shares, it is divided into VC-backed and Non-VC-backed enterprises.

A2: IPO consists of four entities, including enterprises, venture capital, securities investment banks and ordinary investors. Of which venture capital, investment banks and investors are risk-neutral.

A3: The model is divided into four periods ( $t 0, t 1, t 2$ and $t 3)$. During the $t 0$ period, the project being good or bad equals quality of equity investment project. The probability of a good project appearing is $\lambda$, i.e. $\operatorname{Prob}\{q=G\}=\lambda \in(0,1)$ and $\operatorname{Prob}\{q=B\}=1-\lambda$. Only informed investors can observe the quality of the project. In the 11 period, the investment bank determines the price of the enterprise's share issuance $p$; during the $\mathrm{t} 2$ period, the average investor determines the 
amount of demand for the stock $\theta_{i}$; during the period of $\mathrm{t} 3$, the enterprise issues dividends to the shareholders.

A4: Venture capital is divided into two types: high reputation venture capital ( $f$ $=H)$ and low reputation venture capital $(f=L)$. The type of venture capital is private information. Assume that the certification function of venture capital is a capability. Because of its rich experience, high reputation venture capital can fully play the role of certification, and can observe the quality of enterprise projects. Low reputation venture capital cannot observe (or select) the quality of enterprise projects, namely: $\operatorname{Prob}(q=G \mid f=H)=1$ and $\operatorname{Prob}(q=G \mid f=L)=\lambda$.

A5: There are two types of enterprise projects supported by venture capital: $q=$ $G$ and $q=B$ type. The random variable $D$ is used to represent the stock dividend of the listed company. The mathematical expectation and variance of the dividend are $0<\mu_{B}=E(D B)<E(D G)=\mu_{G}$ and $\operatorname{Var}(D B)=\operatorname{Var}(D G)=\sigma^{2}>0$, Among them, $\mu_{B}, \mu_{G}$ and $\sigma^{2}$ are known parameters.

A6: Assume that the securities investment bank signs a stock underwriting contract with the enterprise. The contract stipulates that the income of the investment bank consists of two parts:

$$
\Pi= \begin{cases}\eta+\alpha \mathrm{Z} p \text { If the underwriting role is finished } \\ \eta & \text { If the underwriting role is finished }\end{cases}
$$

If the investment bank can sell the stock of quantity $Z$ at the price $p$ specified by the contract, the investment bank obtains the profits of $a p Z$, where $a \geq 0$ is a known parameter. If the underwriting role is finished or not, the investment bank can obtain profit of $\eta \geq 0$.

A7: There are $N_{1} \geq 1$ informed investors and $N_{u} \geq 1$ uninformed investors in the stock market. And only informed investors can observe the type of enterprise. Each investor has a cash asset $x$ at the beginning of the period. If the investor purchases a stock of quantity $\theta$ at price $p$, then the investor's asset value at the end of the period is:

$$
W_{i}=\theta_{i}+\left(x_{i}-\theta_{i} p\right)(1+r)
$$

where $i=I$, $U$ represents the investor type, $r>0$ is the given risk-free return on assets. The investor utility function defined by Rock (1986) is:

$$
V_{i}=E\left(W_{i} \mid I_{i}\right)-\frac{A}{2} \operatorname{Var}\left(W_{i} \mid I_{i}\right)
$$

where $A>0$ is a known parameter. The investor type is the investor's private information.

A8: Assumption

$$
\mu_{G}-\mu_{B}>A Z \sigma^{2} \max \left[\frac{1}{(1-\lambda) N_{i}}, \frac{1}{\lambda N_{u}}\right]
$$

And

$$
(1-\lambda) \mu_{B}>\frac{A Z \sigma^{2}}{N_{u}}
$$




\section{The Pricing of IPO by Investment Banks and Venture Capital}

1) Total demand for stocks

Proposition 1: The total demand of investors for newly listed stocks is

$$
\theta(p)=\theta_{u}(p)+\theta_{1}(p)
$$

among them,

$$
\begin{gathered}
\theta_{u}(p)=N_{u} \max \left(0, \bar{\theta}_{u}^{G}(p)\right)=N_{u} \max \left(0, \frac{\lambda \mu_{G}+(1-\lambda) \mu_{B}-p(1+r)}{A \sigma^{2}}\right) \\
\theta_{l}(p)=\left\{\begin{array}{l}
N_{l} \max \left(0, \bar{\theta}_{l}^{G}(p)\right)=N_{l} \max \left(0, \frac{\mu_{G}-p(1+r)}{A \sigma^{2}}\right), \text { If } q=G \\
N_{l} \max \left(0, \bar{\theta}_{l}^{g}(p)\right)=N_{l} \max \left(0, \frac{\mu_{g}-p(1+r)}{A \sigma^{2}}\right), \text { If } q=B
\end{array}\right.
\end{gathered}
$$

Proof: If the investor's initial cash asset is $X_{i}$ and the stock of quantity $\theta_{i}$ is purchased at price $p$, then the total amount of assets at the end of the period is $W_{i}=\theta_{i} D+\left(X_{i}-\theta_{i} p\right)(1+r)$. The mathematical expectation and variance of the total assets at the end of the period are:

$$
\begin{gathered}
E\left(W_{i} \mid I_{i}\right)=\theta_{i} E\left(D \mid I_{i}\right)+\left(x_{i}-\theta_{i} p\right)(1+r) \\
\operatorname{Var}\left(W_{i} \mid I_{i}\right)=\theta_{i}^{2} \operatorname{Var}\left(D \mid I_{i}\right)
\end{gathered}
$$

The expected dividends and variances of informed investors and uninformed investors are:

$$
\begin{gathered}
E\left(D \mid I_{i}\right)= \begin{cases}\mu_{G} & \text { If } q=G \\
\mu_{B} & \text { If } q=B\end{cases} \\
E\left(D \mid I_{i}\right)=\lambda \mu_{G}+(1-\lambda) \mu_{B} \\
\operatorname{Var}\left(D \mid I_{i}\right)=\operatorname{Var}\left(D \mid I_{u}\right)=\sigma^{2}
\end{gathered}
$$

According to formulas (3) (9) and (10), the expected utility of investors is:

$$
\begin{aligned}
V_{i} & =E\left(W_{i} \mid I_{i}\right)-\frac{A}{2} \operatorname{Var}\left(W_{i} \mid I_{i}\right) \\
& =\theta_{i} E\left(D \mid I_{i}\right)+\left(x_{i}-\theta_{i} p\right)(1+r)-(A / 2) \theta_{i}^{2} \operatorname{Var}\left(D \mid I_{i}\right)
\end{aligned}
$$

The utility function of informed investors and uninformed investors can be obtained separately:

$$
\begin{aligned}
& V_{l}=\left\{\begin{array}{l}
\theta_{i} u_{G}+\left(x_{i}-\theta_{i} p\right)(1+r)-(A / 2) \theta_{l}^{2} \sigma^{2}, \quad q=G \\
\theta_{i} u_{B}+\left(x_{i}-\theta_{i} p\right)(1+r)-(A / 2) \theta_{l}^{2} \sigma^{2}, \quad q=B
\end{array}\right. \\
& V_{u}=\theta_{u}\left[\lambda \mu_{G}+(1-\lambda) \mu_{B}\right]+\left(x_{u}-\theta_{u} p\right)(1+r)-(A / 2) \theta_{u}^{2} \sigma^{2}
\end{aligned}
$$

Considering the unconstrained investor optimization problem first. Let $\bar{\theta}_{i}(p)$ represent the average individual demand under short-sell conditions. According to Equation (11), the first-order condition of the investor optimization problem is: 


$$
0=E\left(D \mid I_{i}\right)-p(1+r)-A \bar{\theta}_{i}(p) \operatorname{Var}\left(D \mid I_{i}\right)
$$

The average individual demand function of the investor is obtained according to the first-order condition:

$$
\begin{aligned}
& \bar{\theta}_{l}(p)=\frac{E\left(D \mid I_{l}\right)-p(1+r)}{A \operatorname{Var}\left(D \mid I_{l}\right)}= \begin{cases}\bar{\theta}_{l}^{H}(p)=\frac{\mu_{G}-p(1+r)}{A \sigma^{2}}, & \text { If } q=G \\
\bar{\theta}_{l}^{L}(p)=\frac{\mu_{B}-p(1+r)}{A \sigma^{2}}, & \text { If } q=B\end{cases} \\
& \bar{\theta}_{u}(p)=\frac{E\left(D \mid I_{u}\right)-p(1+r)}{A \operatorname{Var}\left(D \mid I_{u}\right)}=\frac{\lambda \mu_{G}+(1-\lambda) \mu_{B}-p(1+r)}{A \sigma^{2}}
\end{aligned}
$$

Since the investor expects utility to be a strictly concave function of the control variable $\theta_{i}$, the $\bar{\theta}_{i}(p)$ determined by the first-order condition is the global optimal solution of the unconstrained optimization problem. The optimization problem is not allowed to sell short-selling as:

$$
\theta_{i}^{*}(p)=\max \left(0, \bar{\theta}_{i}(p)\right)= \begin{cases}\bar{\theta}_{i}(p) & \text { If } \bar{\theta}_{i}(p)>0 \\ 0 & \text { If } \bar{\theta}_{i}(p) \leq 0\end{cases}
$$

Thus get:

$$
\begin{aligned}
& \theta_{u}(p)=N_{u} \max \left(0, \bar{\theta}_{u}(p)\right)=N_{u} \max \left(0, \frac{\lambda \mu_{G}+(1-\lambda) \mu_{B}-p(1+r)}{A \sigma^{2}}\right) \\
& \theta_{l}(p)= \begin{cases}N_{l} \max \left(0, \bar{\theta}_{l}^{G}(p)\right)=N_{l} \max \left(0, \frac{\mu_{G}-p(1+r)}{A \sigma^{2}}\right), & \text { If } q=G \\
N_{l} \max \left(0, \bar{\theta}_{l}^{B}(p)\right)=N_{l} \max \left(0, \frac{\mu_{B}-p(1+r)}{A \sigma^{2}}\right), & \text { If } q=B\end{cases}
\end{aligned}
$$

The total demand of investors for newly listed stocks is:

$$
\theta(p)=\theta_{u}(p)+\theta_{1}(p)
$$

2) Pricing of stocks by investment banks in the risk-free investment

Proposition 2: In the case of satisfying the two hypotheses of Equation (4) and Equation (5), the investment bank in the case of risk-free investment will price the selected stock as $p^{*}$.

$$
p^{*}=\frac{1}{1+r}\left(\lambda \mu_{G}+(1-\lambda) \mu_{B}-\frac{Z A \sigma^{2}}{N_{u}}\right)
$$

Proof: The investor demand curve for Equation (7) and Equation (8) is represented by Figure 1.

As can be seen from the analysis in Figure 1, before the intersection of the straight line $\theta_{U}$ and the straight line $\theta_{P}$, the type $U$ investor has the highest total demand for newly listed stocks; after the intersection, the type I investor has the highest total demand for the new stock of type G. The details are as follows:

As shown in Figure 1, the intersection of the three lines and the horizontal axis is: 


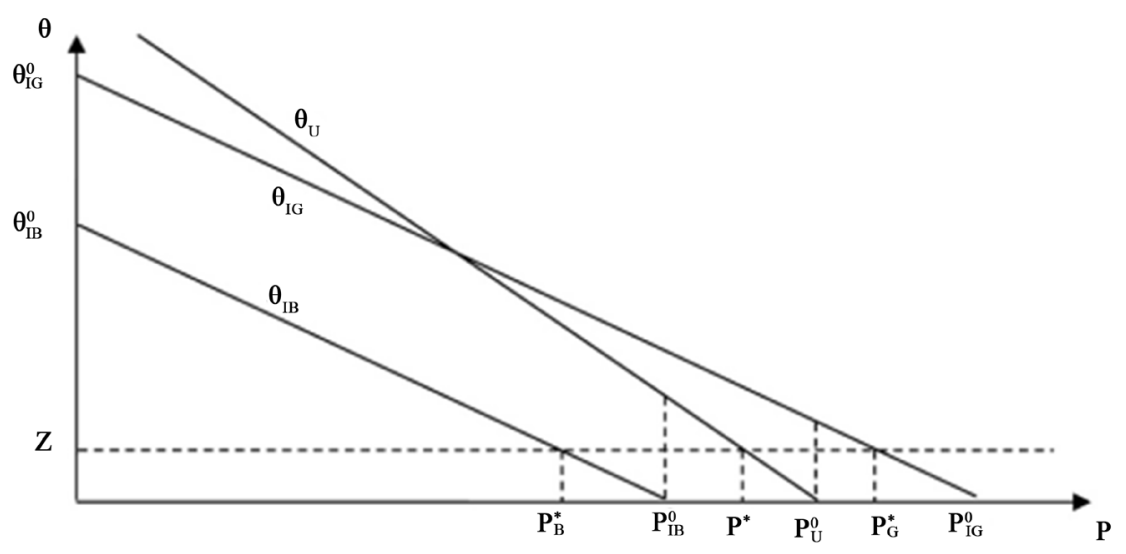

Figure 1. The investor demand curve.

$$
P_{I G}^{0}=\frac{\mu_{G}}{1+r}, P_{I B}^{0}=\frac{\mu_{B}}{1+r}, P_{U}^{0}=\frac{\lambda \mu_{G}+(1-\lambda) \mu_{B}}{1+r} \text { and } P_{I G}^{0}>P_{U}^{0}>P_{I B}^{0}
$$

The intersection of the three straight lines and the vertical axis is:

$$
\theta_{I B}^{0}(p=0)=\frac{N_{1} \mu_{B}}{A \sigma^{2}}, \theta_{I G}^{0}(p=0)=\frac{N_{1} \mu_{G}}{A \sigma^{2}}, \theta_{U}^{0}=\frac{N_{U}\left[\lambda \mu_{G}+(1-\lambda) \mu_{B}\right]}{A \sigma^{2}}
$$

Let $p_{B}^{*}, p_{G}^{*}$, and $p^{*}$ denote the intersection of $\theta=Z$ and three straight lines respectively.

From Equation (8), let $\theta=\left(p_{G}^{*}\right)=N_{1}\left(\frac{\eta_{G}-P_{G}^{*}(1+r)}{A \sigma^{2}}\right)=Z$ and get the following formula:

$$
P_{G}^{*}=\frac{1}{1+r}\left(\mu_{G}-\frac{Z A \sigma^{2}}{N_{1}}\right)
$$

$P_{G}^{*}$ indicates that under the conditions of a high-quality enterprise project, the price of new shares that depended on be finished by informed investors.

From Equation (8), let $\theta=\left(p_{B}^{*}\right)=N_{1}\left(\frac{\mu_{G}-P_{B}^{*}(1+r)}{A \sigma^{2}}\right)=Z$ and get the following formula:

$$
P_{B}^{*}=\frac{1}{1+r}\left(\mu_{B}-\frac{Z A \sigma^{2}}{N_{1}}\right)
$$

$P_{B}^{*} \quad$ indicates the price of new shares that can be completed by underwriting investors under the conditions of low-quality enterprises.

From Equation (7), let $\theta_{u}=\left(p^{*}\right)=N_{u}\left(\frac{\lambda \mu_{G}+(1+\lambda) \mu_{G}-P^{*}(1+r)}{A \sigma^{2}}\right)=Z$, and get the following formula:

$$
P^{*}=\frac{1}{1+r}\left(\lambda \mu_{G}+(1-\lambda) \mu_{B}-\frac{Z A \sigma^{2}}{N_{U}}\right)
$$

$p^{*}$ means that under the condition that the investor is unaware of the enter- 
prise type. Informed investors can finish the pricing of new shares for underwriting role.

$$
\begin{aligned}
& \text { if } \theta_{I G}\left(P_{U}^{0}\right)>\theta_{I G}\left(P_{G}^{*}\right) \text {, ie when } \mu_{G}-\mu_{B}>\frac{Z A \sigma^{2}}{N_{U}(1-\lambda)}, P_{G}^{*}>P_{U}^{0} \text {; } \\
& \text { if } \theta_{U}\left(P_{I B}^{0}\right)>\theta_{U}\left(P^{*}\right) \text {, ie when } \mu_{G}-\mu_{B}>\frac{Z A \sigma^{2}}{N_{U} \lambda}, P^{*}>P_{I B}^{0}
\end{aligned}
$$

Therefore, according to formula (4):

$$
\begin{aligned}
& P_{B}^{*}<P_{I B}^{0}<P^{*}<P_{U}^{0}<P_{G}^{*}<P_{I G}^{0} \\
& (1-\lambda)\left(\mu_{G}-\mu_{B}\right)-\frac{Z A \sigma^{2}}{N_{1}} \geq 0
\end{aligned}
$$

then,

$$
P_{G}^{*}-P^{*}=(1-\lambda)\left(\mu_{G}-\mu_{B}\right)-\frac{Z A \sigma^{2}}{N_{1}}+\frac{Z A \sigma^{2}}{N_{U}} \geq \frac{1}{1+r}\left(\frac{Z A \sigma^{2}}{N_{U}}\right)>0
$$

according to formula (4):

$$
\lambda\left(\mu_{G}-\mu_{B}\right)-\frac{Z A \sigma^{2}}{N_{U}} \geq 0
$$

Then,

$$
\begin{aligned}
p^{*}-p_{B}^{*} & =\frac{1}{1+r}\left(\lambda \mu_{G}+(1-\lambda) \mu_{B}-\frac{Z A \sigma^{2}}{N_{U}}-\left(\mu_{B}-\frac{Z A \sigma^{2}}{N_{l}}\right)\right) \\
& =\frac{1}{1+r}\left(\lambda\left(\mu_{G}-\mu_{B}\right)-\frac{Z A \sigma^{2}}{N_{U}}+\frac{Z A \sigma^{2}}{N_{l}}\right) \\
& \geq \frac{1}{1+r}\left(\frac{Z A \sigma^{2}}{N_{l}}\right)>0
\end{aligned}
$$

according to formula (7):

$$
\begin{aligned}
\bar{\theta}_{U}\left(p_{G}^{*}\right) & =\frac{\lambda \mu_{G}+(1-\lambda) \mu_{B}-p_{G}^{*}(1+r)}{A \sigma^{2}} \\
& =-\frac{(1-\lambda)\left(\mu_{G}-\mu_{B}\right)}{A \sigma^{2}}+\frac{\mu_{G}-p_{G}^{*}(1+r)}{A \sigma^{2}} \\
& =-\frac{(1-\lambda)\left(\mu_{G}-\mu_{B}\right)}{A \sigma^{2}}+\frac{Z}{N_{l}} \leq-\frac{Z}{N_{l}}+\frac{Z}{N_{l}} \\
& =0
\end{aligned}
$$

Means that when the stock is priced at $P_{G}^{*}$, the uninformed investor demand for the new shares is equal to zero (the demand cannot be less than zero).

According to formula (7):

$$
\begin{aligned}
\theta_{U}\left(P_{G}^{*}\right) & =N_{U} \max \left(0, \bar{\theta}_{U}\left(P_{G}^{*}\right)\right)=0 \\
\theta\left(P_{G}^{*}\right) & =N_{l} \bar{\theta}_{l}^{G}\left(P_{G}^{*}\right)+N_{U} \bar{\theta}_{U}\left(P_{G}^{*}\right)=N_{l} \bar{\theta}_{l}^{G}\left(P_{G}^{*}\right) \\
& =N_{l}\left(\frac{\mu_{G}-P_{G}^{*}(1+r)}{A \sigma^{2}}\right)=N_{l}\left(\frac{Z}{N_{l}}\right)=Z
\end{aligned}
$$


It means that when the stock is priced at $p_{G}^{*}$, the demand for new shares by uninformed investors is equal to zero, and the demand for new shares by informed investors in the case of high quality enterprise projects is equal to $Z$.

The aggregate demand of stocks is:

$$
\begin{aligned}
\theta(p) & =\theta_{l}(p)+\theta_{U}(p)=N_{l} \bar{\theta}_{l}(p)+N_{U} \bar{\theta}_{U}(p) \\
& = \begin{cases}N_{l} \bar{\theta}_{l}^{G}\left(P_{G}^{*}\right)=Z & \text { if } p=p^{*}, q=G \\
N_{l} \bar{\theta}_{l}^{B}\left(P_{G}^{*}\right)=0 & \text { if } p=p^{*}, q=B \\
N_{l} \bar{\theta}_{l}^{G}\left(P_{G}^{*}\right)+N_{U} \bar{\theta}_{U}\left(P_{G}^{*}\right)>Z & \text { if } p=p^{*}, q=G \\
N_{U} \bar{\theta}_{U}\left(P_{G}^{*}\right)=Z & \text { if } p=p^{*}, q=B\end{cases}
\end{aligned}
$$

In the interval $\left[P^{*}, P_{G}^{*}\right]$, the minimum demand of investors is $Z$, but since the probability of good project occurrence is $\lambda$, the investment bank can complete the stock underwriting task with probability $\lambda$. The expected payment function of an investment bank is:

$$
E(\pi)= \begin{cases}\eta & \text { if } p>p^{* G} \\ \eta+\lambda \alpha p Z & \text { if } p^{*}<p \leq p^{* G} \\ \eta+\alpha p Z & \text { if } p \leq p^{*}\end{cases}
$$

If $P^{*}<P \leq P_{G}^{*}$, then, $\eta+\lambda \alpha P Z<\lambda \alpha P_{G}^{*} Z$.

According to assumption (5) get:

$$
\begin{aligned}
p^{*}<p \leq p_{G}^{*} & =\frac{1}{1+r}\left(\lambda \mu_{G}+(1-\lambda) \mu_{B}-\frac{Z A \sigma^{2}}{N_{U}}-\lambda\left(\mu_{G}-\frac{Z A \sigma^{2}}{N_{l}}\right)\right) \\
& =\frac{1}{1+r}\left((1-\lambda) \mu_{B}-\frac{Z A \sigma^{2}}{N_{U}}+\lambda\left(\frac{Z A \sigma^{2}}{N_{l}}\right)\right)>\frac{\lambda}{1+r}\left(\frac{Z A \sigma^{2}}{N_{l}}\right)>0
\end{aligned}
$$

Therefore,

$$
\left(\eta+\alpha p^{*} Z\right)-\left(\eta+\lambda \alpha p_{G}^{*} Z\right)=\left(P^{*}-\lambda p_{G}^{*}\right) \alpha Z>0
$$

Under the motive of profit maximization and condition of risk-free investment funds, the investment bank's optimal stock price for the company is $p^{*}$.

3) Stock pricing under the condition of venture capital funds: Separation Equilibrium

Proposition 3: Under the conditions of Proposition 1 and Proposition 2, there is separating equilibrium between the pricing gaming sell between the venture capital and investment banks. In which the conditions, there are $P^{\#} H \in\left(P^{*}, P_{G}^{*}\right)$, so that the pricing strategy of the new shares is:

$$
p^{\#}= \begin{cases}p^{\#} H, & \text { if } q=G \\ p^{*} & \text { if } q=B\end{cases}
$$

The investment bank's beliefs are: $P(f=H \mid q=G)=1$ and $P(f=H \mid q=B)=\lambda$.

Proof: Investment banking is a completely competitive industry, and the pricing of new shares depends more on the decision of venture capital funds. The foregoing explains that the investment bank's expected payment function is (17) 
in the IPO market where no venture capital fund is involved. The issue price that the investment bank is willing to consider may only appear in the interval $\left[P^{*}, P_{G}^{*}\right]$, and the issue price of the new share determined entirely by the investment bank is $p^{*}$. If the venture capital fund participates in IPO market, the new share issuance price $P^{\sharp}$ must satisfy the investment bank's participation constraint, that is, the $P^{\sharp}$ must enable the investment bank to obtain an expected payment of not less than $E\left(\pi \mid P^{*}\right)$. In other words, the IPO price must meet the condition $P^{*} \leq P^{\#} \leq P_{G}^{*}$. According to (17), after the exclusion of $P^{\#}>P_{G}^{*}$, the venture capital fund of type $f=L$ cannot observe the type of the enterprise, so its expected payment is:

$$
E\left(\Omega_{H}\right)= \begin{cases}-\eta+\lambda(1-\alpha) p Z, & \text { if } p^{*}<p<p^{*{ }_{G}} \\ -\eta+(1-\alpha) p Z, & \text { if } p<p^{*}\end{cases}
$$

As,

$$
\left[-\eta+(1-\alpha) P^{*} Z\right]-\left[-\eta+\lambda(1-\alpha) P_{G}^{*} Z\right]=(1-\alpha)\left(P^{*}-\lambda p_{G}^{*}\right) Z>0
$$

According to the hypothesis of Proposition 2, it can be inferred that the optimal new stock of venture capital of type $f=L$ is pricing as: $p^{\#}=p^{*}$. Because a venture capital fund of type $f=H$ can observe and select the type of firm, its expected return is: $E\left(\Omega_{H}\right)=-\eta+(1-\alpha) P Z$, if $P^{*} \leq P \leq P_{G}^{*}$, the objective function is a strictly increasing function of the price $p$.

If the venture capital fund has full bargaining power in determining the IPO pricing, then $P^{\#}=P_{G}^{*}$ is the optimal pricing. Under the condition that the bargaining power is not complete, there is $P_{G}^{\#} \in\left(P^{*}, P_{G}^{*}\right)$, so that under the equilibrium condition, the new shares proposed by the venture capital fund are priced as:

$$
P^{*}= \begin{cases}P_{G}^{*} & \text { if } q=G \\ P^{*} & \text { if } q=B\end{cases}
$$

The investment bank's belief is: $P(q=G \mid f=H)=1$ and $P(q=G \mid f=L)=\lambda$.

If $0<P(q=G)<1$, according to the Bayesian formula, the posterior distribution of the venture capital fund type is:

$$
\begin{aligned}
& p\left(f=H \mid p=p_{G}^{*}\right) \\
& =\frac{p(f=H) p\left(p=p_{G}^{*} \mid f=H\right)}{p(f=H) p\left(p=p_{G}^{*} \mid f=H\right)+p(f=L) p\left(p=p_{G}^{*} \mid f=L\right)} \\
& =\frac{p(q=G) \cdot 1}{p(f=H) \cdot 1+p(f=L) \cdot 0}=1 \\
& p\left(f=L \mid p=p^{*}\right) \\
& =\frac{p(f=L) p\left(p=p^{*} \mid f=L\right)}{p(f=H) p\left(p=p_{G}^{*} \mid f=H\right)+p(f=L) p\left(p=p^{*} \mid f=L\right)} \\
& =\frac{p(f=L) \cdot 1}{p(f=H) \cdot 0+p(f=L) \cdot 1}=1
\end{aligned}
$$


That is, the investment bank can accurately determine the type of venture capital fund through the issue price proposed by the venture capital fund. It's easy to see:

$$
E\left(\Omega_{L} \mid P_{G}^{\#}\right)=-\eta+\lambda(1-\alpha) P_{G}^{\#} Z<-\eta+(1-\alpha) P^{*} Z=E\left(\Omega_{L} \mid P^{*}\right)
$$

That is, a venture capital fund of type $f=L$ cannot obtain a higher expected payment by mimicking the behavior of $f=H$. Meanwhile,

$$
E\left(\Omega_{H} \mid P^{*}\right)=-\eta+(1-\alpha) P^{*} Z<-\eta+(1-\alpha) P_{G}^{\#} Z=E\left(\Omega_{H} \mid P_{G}^{\#}\right)
$$

That is, venture capital funds of type $f=H$ cannot obtain higher expected payments by mimicking the behavior of $f=L$.

The above analysis proves that $p^{\#}$ constitutes a separation and equilibrium strategy for venture capital funds.

Conclusion: Under the condition of venture capital, the price of new shares is the result of bargaining by venture capital funds and investment banks. Under the condition of separation and equilibrium, investment banks can accurately distinguish the types of two types of venture capital through observation; the strategy of venture capital is consistent with the belief of investment banks.

Corollary 1: The high-reputation VC-backed company's stock issuance pricing is higher than the average price of a low-profile VC-backed corporate IPO.

According to Proposition 3, there is a separation and equilibrium in the pricing of new shares proposed by high reputation venture capital funds. When the quality of the enterprise is $q=B$, the pricing of new shares is determined by the investment bank, which is consistent with the pricing of Non-VC-backed enterprises; when the quality of the enterprise is $q=G$, the pricing of new shares is determined jointly by the venture capital fund and the investment bank, and the pricing is high. Pricing as determined by the investment bank alone. Therefore, as long as the number of high-reputation ventures is no less than one, high-profile VC-backed firms are more expensive than the average price of low-profile VC-backed corporate IPOs.

Corollary 2: VC-backed companies' stock offering pricing is higher than the average price of Non-VC-backed corporate IPOs.

Similar to the logic of Inference 1, as long as the number of high-reputation ventures is not less than 1 , the average price of VC-backed companies is higher than the average price of Non-VC-backed corporate IPOs.

\section{Calculation of Underpricing}

Proposition 4: Under the premise of market efficiency, the underpricing between the stock price selected by the investment bank and the market valuation is:

$$
P^{* *}-p^{*}=\frac{1}{1+r}\left(\frac{Z A \sigma^{2}}{N_{U}}\right)
$$

Participating in stock pricing with venture capital will reduce the underpricing of good quality companies and have no impact on worse ones. 
Proof: Under the premise of effective market, the discounted formula according to cash flow can calculate the market valuation of the stock as:

$$
P^{* *}=\frac{1}{1+r}\left(\lambda \mu_{G}+(1-\lambda) \mu_{B}\right)
$$

Therefore the underpricing is:

$$
P^{* *}-P^{*}=\frac{1}{1+r}\left(\frac{Z A \sigma^{2}}{N_{U}}\right)
$$

According to the conclusion of Proposition 3, high reputation venture capital will participate in stock pricing according to the quality of the participating companies' projects. If the enterprise project is of good quality, it will determine higher stock pricing $P_{G}^{\#} \in\left(P^{*}, P_{G}^{*}\right]$ it will reduce underpricing.

\section{Research Contribution and Limitations}

\section{1) Conclusion}

According to the investment bank and venture capital pricing model of this paper, the following conclusions can be drawn. a) In order to attract uninformed investors to participate in the issuance of new shares, investment banks, driven by the motive of maximizing profits, will reduce the issue price of stocks, thereby causing the price of stocks to be underpricing. b) The "certification role" of high reputation venture capital can improve the ability to identify the quality of enterprise projects. Under the drive of profit maximization, venture capital will increase the issue price of high-quality enterprise stocks in the bargaining with investment banks, thus reducing underpricing of stock issuance prices, low reputation venture capital without this effect. c) High-reputation VC-backed enterprise's stock issuance pricing is higher than the average price of low-reputation VC-backed corporate IPOs, VC-backed corporate stock issuance. Pricing is higher than when pricing a NonVC-backed enterprise IPO.

2) Finite analysis

The conclusions of this paper are for entrepreneurs; when they choose financing for financing, they not only pay attention to the financing amount, but also pay attention to the market power of venture capital in the capital market, laying a foundation for its smooth public offering of stock financing in the future. Because of the participation of venture capital, it is possible to attract more market participants to participate in order to ensure the smooth progress of the IPO and the good performance in the secondary market. For regulators, the market power of venture capital covers important players in the capital market. From an economic point of view, the existence of market forces will affect prices, and will lead to monopolistic tendencies, market forces of venture capital. Whether the formation will bring some regulatory gaps is worthy of further study.

3) Research contribution

Based on the supervision and certification hypothesis, this paper constructs the pricing model of investment banking and venture capital, explains the pric- 
ing mechanism of investment banking and venture capital and the reasons for the underpricing. However, due to the lack of knowledge and limited resources, this paper still exist some problems which have not been resolved. Since I did not involve the study of quantitative knowledge, the assumptions about the model can only be finalized, and only the relationship between them can be qualitatively described, and no empirical research is conducted.

\section{Conflicts of Interest}

The author declares no conflicts of interest regarding the publication of this paper.

\section{References}

[1] Logue, D.E. (1973) On the Pricing of Unseasoned Equity Issues: 1965-1969. Journal of Financial and Quantitative Analysis, 8, 91-103. https://doi.org/10.2307/2329751

[2] Rock, K. (1986) Why New Issuers Are Underpriced. Journal of Financial Economics, 15, 187-212. https://doi.org/10.1016/0304-405X(86)90054-1

[3] Lundtofte, F. (2010) A Note on the Pricing of IPOs. Economics Letters, 106, 105-107. https://doi.org/10.1016/j.econlet.2009.10.014

[4] Barry, C.B., Muscarella, C.J., Peavy III, J.W. and Vetsuypens, M.R. (1990) The Role of Venture Capital in the Creation of Public Companies: Evidence from the Going Public Process. Journal of Financial Economics, 27, 447-471. https://doi.org/10.1016/0304-405X(90)90064-7

[5] Megginson, W.L. and Weiss, K.A. (1991) Venture Capitalist Certification in Initial Public Offerings. The Journal of Finance, 46, 879-903. https://doi.org/10.1111/j.1540-6261.1991.tb03770.x 